\title{
Adolescência, situação de rua e exploração sexual: um estudo de caso
}

\author{
Márcia Moraes Lima Coutinho \\ Universidade de Fortaleza - Unifor, CE, Brasil \\ Rebeca Fernandes Ferreira Lima \\ Universidade de Fortaleza - Unifor, CE, Brasil \\ Normanda Araujo de Morais' \\ Universidade de Fortaleza - Unifor, CE, Brasil
}

\begin{abstract}
Resumo: Trata-se de um estudo de caso de um adolescente em situação de rua, 17 anos de idade, sexo masculino, homossexual e vítima da exploração sexual (ES). O estudo teve como objetivo descrever, em sua trajetória de vida, os condicionantes relacionados ao ingresso na $\mathrm{ES}$, à permanência nela e à saída dela. Foram realizadas três entrevistas. O envolvimento com a ES começou aos I 2 anos com a finalidade de ajudar financeiramente a família e custear o uso de drogas do adolescente. Sublinha-se o envolvimento com a rua que teve relação com a possibilidade de vivência da homossexualidade e da travestilidade. Alguns fatores na trajetória de vida, como namorar, trabalhar e ter sua moradia, contribuíram para saída da ES e interrupção do uso de drogas. Verificaram-se múltiplas violências na trajetória do adolescente, entretanto, destacam-se as relações de afeto e as oportunidades de melhoria das condições de vida como fatores potenciais para enfrentamento da ES.
\end{abstract}

Palavras-chave: exploração sexual; situação de rua; gênero; meninos; adolescentes.

\section{ADOLESCENCE, STREET SITUATION AND SEXUAL EXPLOITATION: A CASE STUDY}

\begin{abstract}
This is a case study of an adolescent in street situation, 17 years old, male, homosexual and victim of sexual exploitation (SE). The objectives of the study were to describe in life trajectory the conditions related to the entrance, permanence and leaving out of SE. We conducted three interviews. Involvement with the SE began to 12 years in order to financially support the family and pay for the adolescent drug use. It emphasizes the involvement with the street that was related to the possibility of living of homosexuality and transvestism. Some factors on the trajectory of life as dating, working and have your housing contributed to leave the SE and interruption of the drug use. Multiple violence was identified in the adolescent's trajectory, however, the relations of affection and opportunities for improvement of the living conditions as potential factors to coping the SE.
\end{abstract}

Keywords: sexual exploration; street situation; gender; boys; adolescents.

1 Endereço de correspondência: Normanda Araujo de Morais: Universidade de Fortaleza, Programa de Pós-Graduação em Psicologia, Avenida Washington Soares, 1321, Edson Queiroz, Fortaleza, CE. CEP: 60.811-905. E-mail: normandaaraujo@gmail.com 
LA ADOLESCENCIA, SITUACIÓN DE CALLE Y LA EXPLOTACIÓN SEXUAL: UN ESTUDIO DE CASO

\begin{abstract}
Resumen: Es un estudio de caso de un adolescente en situación de calle, 17 años, sexo masculino, homosexual y víctima de la explotación sexual (ES). El objetivo es describir en su trayectoria de vida los condicionantes relacionados al ingreso, permanencia y salida de la ES. Fueron realizadas tres entrevistas. La participación con la ES comenzó a los 12 años para ayudar económicamente a la familia y costear el uso de drogas del adolescente. La implicación con la calle tuvo relación con la posibilidad de vivencia de la homosexualidad y travestismo. Algunos factores en la trayectoria de vida como enamorar, trabajar y tener su propia casa contribuyeron con la salida de la ES e interrupción del uso de drogas. Se verificaron múltiples violencias en su trayectoria, se destacan las relaciones de afecto y las oportunidades de mejora de las condiciones de vida como factores potenciales para el enfrentamiento de la ES.
\end{abstract}

Palabras clave: explotación sexual; situación de calle; género; niños; adolescentes.

\title{
Introdução
}

A trajetória de adolescentes em situação de rua revela uma série de dificuldades na família e fracassos nas políticas sociais, no sistema educacional e na rede de instituições que devem preservar e garantir seus direitos fundamentais, como promulga o Estatuto da Criança e do Adolescente - ECA (1990). Ao saírem para as ruas, os adolescentes buscam condições de vida melhores que as anteriores, que se caracterizam por pobreza, conflito e violência intrafamiliar, entre outras adversidades que resultam no enfraquecimento dos vínculos familiares e comunitários. Embora a ida para a rua seja por busca de sobrevivência e bem-estar, esse contexto expõe os adolescentes a diversos riscos, como uso de drogas, trabalho infantil e exploração sexual (Morais, Neiva-Silva, \& Koller, 2010).

Especificamente, a exploração sexual de crianças e adolescentes (Esca) é uma forma de violência sexual, assim como o abuso sexual também o é. A principal diferença entre esses dois tipos de violência refere-se ao aspecto comercial que a primeira (Esca) pressupõe. O abuso sexual é toda prática sexual, em relação heterossexual ou homossexual, na qual os agressores estão em estágio de desenvolvimento psicossexual mais adiantado que a criança ou o adolescente (Ministério da Saúde, 2002). Já a Esca é definida como uma ação que envolve a manipulação do corpo de crianças/adolescentes, independentemente do gênero, para obtenção de algum tipo de vantagem ou proveito sexual, sendo esta baseada em uma relação de poder e de exploração comercial (Cerqueira-Santos, Rezende, \& Correia, 2010).

A Esca no Brasil se manifesta de forma diversificada e particularizada a depender de cada região brasileira (Leal, 1999). De acordo com Leal (1999), a Esca, nos centros urbanos, envolve adolescentes em situação de rua, contexto de pobreza extrema e violência intrafamiliar (física, emocional e/ou sexual). Esses jovens utilizam o próprio corpo como meio de obter afeto e sustento (necessidades básicas e/ou consumo de drogas, por exemplo).

A identificação da relação entre a problemática econômica, o acúmulo de violências e a exploração sexual denuncia a situação de risco pessoal e social dos adolescentes 
que estão submetidos à mercantilização de seus corpos para sobrevivência própria e de familiares. A exploração sexual é, portanto, uma violência de diferentes níveis, desde situações de risco pessoal até problemas de ordem estrutural, de gênero, classe social, etnia, idade, orientação sexual, bem como de violência física, sexual e psicológica (Alberto, Lima, \& Macêdo, 2014; Libório, 2005). Assim, a Esca é investigada como um fenômeno que envolve múltiplos determinantes (por exemplo, sociais, econômicos e culturais). É considerada como uma das formas mais extremas da violação dos direitos humanos (Bellenzani \& Malfitano, 2006) e uma das piores formas de trabalho infantil (Organização Internacional do Trabalho, 1999).

No geral, quanto ao perfil dos adolescentes vitimados na Esca, a maioria é da região nordeste, do sexo feminino, afrodescendente, com baixa renda e baixa escolaridade, e sofreu abuso sexual. Além disso, a maioria engravidou precocemente, está submetida à exploração de pessoas muito próximas (colegas, amigos da família e namorados) e reside com a família (mesmo tendo vínculo com a rede de instituições); e entre aqueles/as que não moram com os pais, é sabido que saíram de casa em razão de conflitos familiares (Alberto et al., 2014; Cerqueira-Santos, 2009).

Em relação às consequências da exploração sexual, identifica-se que os adolescentes são expostos a situações de risco à saúde, como doenças sexualmente transmissíveis (DST), infecção pelo HIV, dependência química, alcoolismo e sofrimento psíquico que podem resultar em suicídio. Outros riscos psicossociais são enumerados, como gravidez indesejada, despreparo para a maternidade e/ou paternidade, adoção de práticas educativas muito rígidas e autoritárias, isolamento social das famílias que evitam desenvolver relações de proximidade com pessoas fora do contexto familiar, ocorrência de práticas parentais hostis ou negligentes em relação aos jovens, insultos e humilhações de pessoas em geral, violência doméstica, ataques sexuais e físicos de clientes e de agenciadores, abuso e detenção da polícia, entre outros prejuízos para a vida e o bem-estar dos adolescentes vítimas da exploração sexual (Alberto et al., 2014; Cerqueira-Santos, 2009; Pedersen, 2009). Entretanto, verifica-se que a presença de vínculo do adolescente com a família e a saída da Esca, bem como a relação da permanência na escola, melhores níveis de autoestima e menores níveis de depressão, apresentam-se como fatores de proteção que podem favorecer o desenvolvimento saudável (Cerqueira-Santos, 2009).

Crianças e adolescentes envolvidos na exploração sexual vivenciam diferentes situações de vulnerabilidade (social, econômica, cultural, política etc.) ao seu desenvolvimento. Tal cenário, por sua vez, está intrinsecamente relacionado à situação de desvantagem e de submissão às relações assimétricas de poder nas quais se colocam quando do seu envolvimento na exploração sexual (Libório, 2004). Assim sendo, a noção de consentimento é deslocada para a ênfase sobre o problema social da Esca, no qual a criança/adolescente está em desvantagem e sua escolha, limitada às opressões que vivencia (Lowenkron, 2015). O contexto de desigualdade biopsicossocial e econômico impõe práticas violentas, e a cultura machista subjuga e legitima o comércio 
sexual, de forma a negar os direitos fundamentais e prejudicar o desenvolvimento saudável das crianças e dos adolescentes (Cerqueira-Santos \& Morais, 2016).

Com destaque às questões de gênero, é importante sublinhar a ocorrência da violência sexual e da exploração de crianças e adolescentes do sexo masculino, sobretudo no que tange às diversidades sexuais (por exemplo, meninos gays, travestis e transexuais). A maioria das pesquisas sobre violência sexual apresenta uma menor incidência desta entre os meninos (Hohendorff, Habigzang, \& Koller, 2012; Hohendorff, Habigzang, Costa, \& Koller, 2014), fato que pode contribuir para a invisibilidade dessa população e a errônea percepção de que meninos não estão submetidos às situações de violência sexual. A lacuna na literatura é ainda maior no tocante à exploração sexual de meninos, uma vez que os estudos tendem a descrever o maior envolvimento na Esca por parte das meninas (por exemplo, Alberto et al., 2014; Cerqueira-Santos, 2009). Essa realidade, por sua vez, contribui para a escassez de informações (psíquicas, sociais e familiares) da exploração sexual em relação às diferenças de gênero (Almeida, Penso, \& Costa, 2009; Hohendorff et al., 2012, 2014).

No sistema social do patriarcado, o indivíduo de gênero masculino tem sua identidade construída fundamentada na virilidade, que impõe a rejeição da fraqueza e do pedido de ajuda, considerando a passividade um atributo da homossexualidade (Xavier Filha, 2008). Assim, problematiza-se que os poucos estudos com os meninos vítimas da exploração sexual têm relação com a subnotificação da violência sexual em meninos de uma forma geral. Almeida et al. (2009) apontaram alguns dos fatores que estariam relacionados à subnotificação, tais como: o medo da homossexualidade - decorrente da representação vigente no senso comum de que meninos que foram abusados se envolverão em práticas homossexuais no futuro; respostas emocionais como a vergonha; falta de monitoramento parental; atribuição da culpa ao menino; dificuldades em perceber indícios de abusos pertinentes a meninos; e negação da violência. Em particular, as preocupações homofóbicas com o futuro do menino levam os pais a escondê-lo da família e vizinhança por receio de discriminação que ele poderá sofrer. Em consequência, tem-se muito frequentemente a negação da violência por meio da instalação do segredo, uma espécie de regra implícita que proíbe falar sobre o assunto.

Diante da escassez de estudos acerca da exploração sexual infantojuvenil masculina, das situações de risco e das consequências negativas para a saúde dos vitimados, o estudo teve como objetivo descrever, em sua trajetória de vida, os condicionantes relacionados ao ingresso na exploração sexual, à permanência nela e à saída dela em entrevistas individuais realizadas em três momentos. As bases para a análise dos dados são da Abordagem Bioecológica do Desenvolvimento Humano (Bronfenbrenner, 1996, 2011; Bronfenbrenner \& Morris, 2006). Nessa abordagem, o desenvolvimento é definido a partir dos processos de interação recíproca e significativa do indivíduo com outras pessoas, objetos e símbolos dos ambientes de inserção social e cultural, sendo resultado de quatro núcleos inter-relacionados: pessoa (características do indivíduo), processo (dinâmica de interações entre o indivíduo e o meio ambiente), contexto (ambientes físicos e sociais que moldam as experiências do dia a dia) e tempo (continuidades e 
descontinuidades da rotina e história). De acordo com essa concepção, pensa-se a vítima da exploração sexual de forma integral (consideração das suas características biopsicossociais), contextualizada e ao longo do tempo.

\section{Método}

Trata-se de um estudo longitudinal, isto é, propõe-se o acompanhamento do participante, verificando suas continuidades e mudanças ao longo do tempo, de delineamento de estudo de caso único. De acordo com Yin (2010), esse delineamento propõe investigar um fenômeno em profundidade e em seu contexto real, possibilitando aos investigadores uma compreensão das características holísticas e significativas da realidade analisada. Este estudo fez parte de uma pesquisa intitulada $O$ impacto da vida na rua em adolescentes: um estudo longitudinal sobre risco e proteção, que buscou acompanhar a trajetória de adolescentes em situação de rua na cidade de Fortaleza, no Ceará, por um período de dois anos.

\section{Participante e procedimentos}

O participante foi um adolescente (17 anos de idade e sexo masculino) em situação de rua, que tinha vínculo com uma instituição de acolhimento na capital cearense. O participante foi selecionado por conveniência e a partir do seguinte critério de inclusão: ter tido experiência de rua há, no máximo, seis meses antes da realização da pesquisa.

As entrevistas individuais foram guiadas por um roteiro com os seguintes temas: 1. história pessoal e familiar; 2. saída de casa (ou ficar muito tempo na rua ou ainda ter uma experiência de risco na rua); 3. vida nas ruas (atual ou anterior); 4. histórico de violência física, emocional e sexual (na família e/ou na rua); 5. experiência escolar e de trabalho; 6 . histórico de institucionalização.

Primeiramente, na instituição de acolhimento, buscou-se uma vinculação com o adolescente para que as entrevistas pudessem acontecer de forma espontânea, de acordo com o método da Inserção Ecológica (Cecconello \& Koller, 2003). Esse método tem como fundamento os processos proximais, o qual envolve processos de interações recíprocas entre pesquisador-participante em uma base regular de tempo, que propiciam ao participante engajamento na entrevista e suporte a ele, quando necessário.

Após concordância do adolescente com o estudo, as entrevistas foram realizadas por uma psicóloga (primeira autora deste artigo), em três momentos com duração de 35 a 45 minutos, com o mínimo de seis meses de intervalo entre cada encontro. Os dois primeiros encontros aconteceram em instituições da rede de proteção e o terceiro na casa da avó do adolescente. Além disso, para garantir a continuidade no acompanhamento do adolescente, entre uma coleta de dados e outra, a pesquisadora fez visitas à instituição, bem como telefonou seguidas vezes para se certificar da situação do adolescente que estava sendo acompanhado. 
As entrevistas foram gravadas e transcritas para posterior análise. O conteúdo das entrevistas foi submetido aos procedimentos de análise propostos por Bardin (1979), com base nas seguintes etapas: pré-análise, exploração do material, tratamento dos resultados e interpretação. Essa análise permitiu identificar os condicionantes para o ingresso e manutenção na Esca e saída dela. Para compreensão e discussão contextualizada dos resultados, utilizou-se a Abordagem Bioecológica (Bronfenbrenner, 1996, 2011; Bronfenbrenner \& Morris, 2006), que propõe a análise das relações entre as pessoas e os contextos, bem como a literatura específica sobre a Esca.

Este estudo teve aprovação do Comitê de Ética da Universidade de Fortaleza, sob protocolo de número 397/2011. Obteve-se assinatura do Termo de Concordância do Ministério Público e da instituição em que ocorreu a inserção da pesquisadora, além do assentimento do adolescente.

\section{Resultados}

\section{Descrição do caso}

Leandro (nome fictício) é um adolescente, do sexo masculino, de 17 anos de idade, que foi criado pela avó desde o nascimento. Sua mãe morreu durante o parto, e o contato com o pai se dava nos finais de semana. Ele tem uma irmã e quatro irmãos. Leandro alegou sofrer violência física e psicológica em casa por parte de familiares, principalmente dos tios. Envolveu-se em ato infracional praticando roubos e furtos e tentativa de assassinato de um tio.

Sua primeira relação sexual foi aos 8 anos, com um vizinho adolescente. Aos 11 anos, começou a usar drogas (álcool, cigarro, maconha, cocaína e crack) e abandonou a escola. Aos 12 anos, começou a se envolver na exploração sexual sem o conhecimento da família, quando saía com a prima para as festas. Sua prima estava envolvida com a exploração sexual e o uso de drogas, sendo a pessoa que o inseriu nos primeiros programas sexuais e facilitava o contato com as drogas. Quando a sua irmã foi expulsa de casa pela avó, também se envolveu com a exploração sexual. $O$ adolescente explicou que, quando chegava em casa de manhã com o dinheiro que ganhava dos "programas" e sua avó o questionava sobre a origem dele, ela, ao saber, chorava e, às vezes, reclamava. Leandro tinha relações sexuais principalmente com homens.

$\mathrm{O}$ adolescente afastou-se de sua família por causa dos conflitos, principalmente, com os tios, que não o queriam morando com a avó, visto seu envolvimento com drogas e sua orientação sexual. Seu pai e tio também eram usuários de drogas. Leandro teve três tentativas de suicídio. Aos 14 anos, saiu de casa para morar com um amigo e a mãe dele. $O$ adolescente continuava envolvido com a exploração sexual e relatou que fazia "programas" na esquina da casa da avó. Parte do dinheiro que ganhava com os "programas" entregava para a mãe de seu amigo. Quando brigava com seu amigo, retornava para as ruas. Leandro considerava seu envolvimento com a exploração sexual como um meio de conseguir dinheiro para comprar drogas. Em seus relatos, ele afirmou que o dinheiro advindo dos "programas" gastava rapidamente, enquanto o 
dinheiro ganho com outro trabalho "gasta com mais cuidado", afirmando: "o dinheiro que eu ganho fácil eu gasto fácil".

Em virtude da dependência química e dos conflitos familiares, Leandro teve uma alta circulação entre diferentes espaços de tutela, tanto na família - transitava pelas casas da avó (que ele chamava de "mãe"), da tia, da irmã e do pai biológico - quanto na rede de instituições, além de frequentar as ruas.

\section{Seguimento do caso ao longo do tempo}

Na primeira entrevista (tempo 1), Leandro encontrava-se em um acolhimento institucional e já tinha estado em outras instituições da cidade, incluindo centros educacionais de privação de liberdade. Nesse momento, o adolescente tinha uma boa vinculação com o contexto institucional, porém, sentia-se extremamente ansioso pela aproximação da maioridade, pois não poderia mais contar com o apoio da rede de instituições para crianças e adolescentes que costumava frequentar.

Após seis meses, na segunda entrevista (tempo 2), o adolescente havia saído da instituição, estava passando a maior parte de seu tempo nas ruas e tinha emagrecido bastante. Considerando uma maior aproximação da pesquisadora com o adolescente, sua maior aceitação identitária, além de uma maior liberdade do contexto da rua, Leandro se apresentou como travesti e relatou que, quando decidiu ser uma "trava" (travesti), comunicou o fato à família. Na ocasião, seus irmãos aceitaram, embora a tia e a avó reclamassem de vez em quando. O pai deu uma surra ao saber de sua decisão. Leandro alegou que a motivação para tanto fora a necessidade de ter dinheiro para custear o uso de drogas.

Passados mais seis meses (um ano após o tempo 1), no último encontro com a pesquisadora (tempo 3), o adolescente mostrava-se satisfeito com sua vida, e sua aparência física aparentava boa saúde. Morava em uma casa que alugou com seu companheiro, trabalhava em uma peixaria e não se envolvia mais com a exploração sexual, e o consumo de drogas estava limitado ao uso de drogas lícitas (álcool e cigarro). As suas preocupações que antes remetiam ao uso de drogas e à exploração sexual foram substituídas por questões domésticas, como ligar para a companhia de água para regularizar o abastecimento em sua casa. Ele não havia retornado à escola e justificou: "lá não dá para mim, tem muitas drogas!". Esse encontro ocorreu na casa de sua avó, demonstrando que, apesar de conflitos vivenciados na família, o adolescente manteve vínculos com sua avó.

\section{Discussão}

Este estudo objetivou apresentar um estudo de caso de um adolescente do sexo masculino em situação de rua, vítima da exploração sexual, descrevendo, em sua trajetória de vida, os condicionantes relacionados ao seu ingresso na exploração sexual, à permanência nela e à saída dela. Empregou-se uma leitura contextualizada da exploração sexual, com base na Abordagem Bioecológica (Bronfenbrenner, 1996, 2011; 
Bronfenbrenner \& Morris, 2006). Nessa perspectiva, foi possível identificar as pessoas e os contextos (família, escola, instituições e rua) significativos ao adolescente ao longo de sua trajetória e envolvimento com a exploração sexual.

A trajetória de vida de Leandro corrobora a literatura acerca das vítimas da exploração sexual sobre a presença de múltiplas situações de risco ao seu desenvolvimento (Alberto et al., 2014; Cerqueira-Santos, 2009; Pedersen, 2009; Hohendorff et al., 2012, 2014). No relato de Leandro são evidentes: violência física e psicológica sofrida no contexto familiar; abuso sexual anterior; alta circulação entre diferentes espaços ( $f a-$ mília, instituições e rua); abandono escolar; dificuldades financeiras; envolvimento em ato infracional (roubos e furtos); uso de drogas e tentativas de suicídio e assassinato do tio; além da exploração sexual. Outros riscos presentes no sistema familiar sobressaem, como pai e tio usuários de drogas e irmã e prima envolvidas na exploração sexual. Diante desses resultados, compreende-se que os processos decisórios que marcam a vinculação de Leandro com a rua estão relacionados às negligências e exclusões multidimensionais socialmente compartilhadas de gênero, classe e raça (Dias et al., 2015).

A alta circulação entre os diferentes espaços de tutela (família e instituições) e a rua denuncia a vulnerabilidade do adolescente. No que se refere ao contexto familiar, evidenciou-se a instabilidade ou mesmo a ausência de um monitoramento mais efetivo esperado para sua idade, revelando o contexto de violência, caracterizado por negligência, conflitos e práticas educativas violentas. Como se pode observar, Leandro relatou que seu envolvimento inicial com a exploração sexual era de desconhecimento da família, entretanto, os "programas" que fazia eram na esquina da casa da avó e o dinheiro recebido complementava a renda familiar. Esses resultados corroboram a perspectiva de instalação do segredo, na qual a violência velada resulta na conivência da exploração sexual, oportunizando a sua perpetuação (Almeida et al., 2009).

Ainda sobre o espaço família, Bronfenbrenner e Morris (2006) afirmaram que, para promoção do desenvolvimento, é necessário que a interação se caracterize pelo afeto, pela confiança e durabilidade. Na trajetória de Leandro, a ausência ou instabilidade nos cuidados parentais foi um dos fatores que podem ter facilitado a ocorrência do abuso sexual na infância e o seu ingresso nas drogas. No que diz respeito ao espaço escola, ela apresentou-se ambígua para Leandro, conforme os próprios relatos em relação à facilidade de acesso às drogas. Dessa forma, a relação de Leandro com a escola era vulnerável, não se caracterizando como um contexto protetivo, além de apresentar riscos diretos ao seu desenvolvimento.

Indica-se, ainda, que as dificuldades financeiras colaboraram para o início e a manutenção do adolescente na exploração sexual comercial, pois, mesmo se afastando da família e indo residir na casa de um amigo, utilizava o dinheiro da exploração sexual para satisfação das necessidades básicas e do espaço doméstico. De acordo com a literatura (Libório, 2005; Pedersen, 2009), é importante destacar a faceta da violência estrutural da exploração sexual. Salienta-se que a pobreza não é entendida como um fator determinante da violência sexual (Cerqueira-Santos \& Morais, 2016). Entretanto, 
a dimensão econômica precisa ser considerada, visto que a pobreza constitui um processo de fragilização social e é, portanto, um indicador de vulnerabilidade que expõe os adolescentes às situações de risco, como a exploração sexual.

Quanto às instituições, verificou-se que o adolescente tinha vínculo com esses espaços, porém havia uma grande rotatividade. Tal cenário, por sua vez, leva à problematização acerca da efetividade da rede de instituições pelas quais Leandro passou ao longo da sua vida. No seu caso em específico, pergunta-se até que ponto as práticas adotadas no cotidiano dessas instituições eram realmente adequadas para lidar com a realidade de Leandro - adolescente em situação de rua, homossexual, travesti e vítima da exploração sexual. Revela-se, portanto, a necessidade de intervenções protetivas que atuem considerando as singularidades dos adolescentes, incluindo as questões de gênero e sexualidade, tradicionalmente tão negligenciadas nesses contextos.

A dificuldade de reconhecimento da rede de instituições como atuante em seu papel de proteção ante a exploração sexual também foi destacada no estudo de Vega e Paludo (2015). Algumas dificuldades apontadas pela literatura referem-se à falta de informações acerca da diferenciação entre abuso sexual e exploração sexual, ao reconhecimento da exploração sexual como uma violência que viola os direitos das crianças/adolescentes e às dificuldades dos próprios serviços no atendimento à exploração sexual comercial. As limitações da rede de instituições ocorrem desde o desconhecimento da legislação, as formas de efetivação de suas competências até a falha na articulação interinstitucional (Alberto, Silva, Gomes, Santana, \& Soares, 2012; Vega \& Paludo, 2015).

No que se refere à rua, notou-se uma crescente vinculação de Leandro com esse ambiente, seja para o uso de drogas ou para os "programas". Evidencia-se, assim, a rua como possibilidade para vivência da travestilidade. Embora o adolescente utilizasse a "montagem" do feminino na busca por programas sexuais, a rua foi um contexto que facilitou os processos de construção da identidade travesti e homossexual. Concomitante aos riscos, problematiza-se que o adolescente elegeu a rua como uma alternativa ante os conflitos e a violência intrafamiliar decorrente do preconceito e da discriminação dos familiares para com sua orientação sexual/identidade de gênero (Morais et al., 2010). No estudo de Dias et al. (2015), a respeito da trajetória de vida de duas mulheres trans, os autores mencionam que a situação de rua e a exclusão pela identidade de gênero são dois elementos fortemente imbricados, à semelhança do que se pôde constatar neste estudo. A partir do preconceito e da não aceitação vivenciados no âmbito familiar, somados ao uso de drogas, Leandro precisou encontrar formas de sustentar sua orientação sexual/identidade de gênero, o que no seu caso implicou a situação de rua e o envolvimento na exploração sexual.

Em relação à escola, apesar de esse contexto estar relacionado a práticas educativas que favorecem bons resultados futuros e qualidade profissional, destacou-se como um ambiente em que o adolescente tinha fácil acesso às drogas. A escola pode ser protetiva e atuar na identificação da exploração sexual, porém, confirmando os achados de 
Vega e Paludo (2015), tem-se identificado que esse contexto não tem sido ativo em sua função de proteção, conforme corrobora o caso de Leandro.

A análise do caso revela aspectos protetivos que influenciaram a saída da Esca. Observou-se que o processo de afirmação homossexual, estar namorando, ter conseguido um emprego e moradia foram fatores que contribuíram para saída da exploração sexual e uso de drogas ilícitas. Assim, salienta-se que a presença de relações mais estáveis entre o adolescente, as pessoas e seu contexto e as melhores condições de vida podem favorecer o desenvolvimento e a saída da Esca. Quando se examinam as características biopsicossociais do entrevistado, notam-se as mudanças pelas quais passou, apresentando-se ao final do estudo com boa aparência e satisfeito com sua vida, diferentemente do primeiro encontro, no qual se mostrava muito ansioso, e do segundo encontro, no qual estava mais magro e com outros sintomas físicos. Diante desses resultados, vislumbra-se que a eficácia de intervenções com adolescentes envolvidos com a Esca deve considerar questões fundamentais para o desenvolvimento saudável, tais como gênero, sexualidade e projeto de vida.

É importante frisar que a família não pode ser responsabilizada pelo ingresso e pela permanência de Leandro na situação de exploração sexual. Deve, ao contrário, ser compreendida a partir de uma concepção complexa capaz de percebê-la como vítima também dessa violência. Nesse sentido, a literatura aponta que as intervenções que busquem interromper o ciclo de violência sugerem atuações e intervenções destinadas a todos os envolvidos na Esca e todos os seus atores - vítimas, famílias, comunidade, profissionais e serviços (Vega \& Paludo, 2015).

Quanto às limitações do estudo, aponta-se que, por este artigo ser oriundo de uma pesquisa mais abrangente sobre o impacto da vida na rua, a temática da exploração sexual esteve presente a partir da história de vida desse participante, emergindo em questionamentos sobre a experiência de eventos adversos de vida, especialmente sobre violência física, psicológica e sexual. Sugere-se que estudos futuros possam se centrar, por exemplo, na investigação dos sentidos e significados atribuídos pelos adolescentes à exploração sexual, no sentido de aprofundar a sua autopercepção, ou seja, se eles percebem a exploração como uma violência, se percebem os riscos trazidos à sua saúde etc. Recomenda-se o investimento em estudos que tenham como foco os processos estabelecidos entre adolescentes em situação de rua vítimas da exploração sexual e as instituições da rede de proteção, buscando verificar fatores protetivos, bem como aspectos de revitimização, relacionados ao preconceito, ao estereótipo e à discriminação.

Este estudo de caso evidencia a importância de perspectivas qualitativas que discutam a exploração sexual em meninos, possibilitando a compreensão das nuances e especificidades da exploração e de suas vítimas, bem como que problematizem a interseção da situação de rua e exploração sexual. Reitera-se a relevância de estudos que priorizem a compreensão da trajetória de vida desses adolescentes, desde sua inserção gradual na rua e os riscos inerentes a esta, a dinâmica da família, até outros contextos significativos ao desenvolvimento que podem facilitar o ingresso e a manu- 
tenção dos meninos na exploração sexual, bem como os fatores protetivos que contribuem para o enfrentamento dessa exploração.

\section{Referências}

Alberto, M. de F., Lima, J. A., \& Macêdo, O. J. V. (2014). A relação entre experiência de abuso e exploração sexual comercial de crianças e adolescentes. In S. C. Baron \& K. T. R. Brasil (Orgs.), Jovem, adolescente e criança em contextos de proteção e de risco no Brasil (pp. 114-146). Niterói: Editora da UFF.

Alberto, M. F. P., Silva, A. C. S., Gomes, V. C., Santana, R. V. M., \& Soares, A. M. (2012). Os agentes sociais da rede de proteção e atendimento no enfrentamento da exploração sexual comercial. Psicologia: Reflexão e Crítica, 25(1), 130-138.

Almeida, T. M. C. de, Penso, M. A., \& Costa, L. F. (2009). Abuso sexual infantil masculino: o gênero configura o sofrimento e o destino? Estilos da Clínica, 14(26), 46-67.

Bardin, L. (1979). Análise de conteúdo (L. Reto \& A. Pinheiro, Trad.). São Paulo: Edições 70. (Obra original publicada em 1977).

Bellenzani, R., \& Malfitano, A. P. S. (2006). Juventude, vulnerabilidade social e exploração sexual: um olhar a partir da articulação entre saúde e direitos humanos. Saúde e Sociedade, 15(3), 115-130.

Bronfenbrenner, U. (1996). A ecologia do desenvolvimento humano: experimentos naturais e planejados. Porto Alegre: Artes Médicas. (Obra original publicada em 1979).

Bronfenbrenner, U. (2011). Bioecologia do desenvolvimento humano: tornando os seres humanos mais humanos (A. C. Barreto, Trad.). Porto Alegre: Artmed.

Bronfenbrenner, U., \& Morris, P. A. (2006). The bioecological model of human development. In W. Damon \& R. M. Lerner (Orgs.), Handbook of child psychology (pp. 793-828). New York: John Wiley.

Cecconello, A. M., \& Koller, S. H. (2003). Inserção ecológica na comunidade: uma proposta metodológica para o estudo de famílias em situação de risco. Psicologia Reflexão e Crítica, 16, 515-524.

Cerqueira-Santos, E. (2009). Vítimas da exploração sexual de crianças e adolescentes: indicadores de risco, vulnerabilidade e proteção. Recuperado em 12 outubro, 2018, de http://www.childhood.org.br/wp-content/uploads/2014/03/vitimas-deexplora\%C3\%A7\%C3\%A3o-sexual-de-crian\%C3\%A7as-e-adolescentes.pdf

Cerqueira-Santos, E., \& Morais, N. A. (2016). Violência e vitimização: o caso da exploração sexual de crianças e adolescentes. In M. Poletto, A. P. L. de Souza, \& A. H. Koller (Orgs.), Escola e educação: práticas e reflexões (pp. 255-268). Curitiba: Juruá. 
Cerqueira-Santos, E., Rezende, N., \& Correia, P. (2010). Adolescentes vítimas de exploração sexual: um estudo de caso múltiplo. Contextos Clínicos, 3(2), 113-123.

Dias, A. L. F., Borges, A. O., Cunha, B. E.B., Castro, B. P., Campos, J. A., Carvalho, M. C. A., \& Martins, V. B. (2015). À margem da cidade: trajetórias de invisibilidade e exclusão de travestis em situação de rua. Gerais: Revista Interinstitucional de Psicologia, 8(2), 214-233.

Estatuto da Criança e do Adolescente (1990). Lei n. 8.069. Brasília, DF: Ministério da Educação.

Hohendorff, J. V., von, Costa, L. S., Habigzang, L. F., \& Koller, S. H. (2014). Documentary analysis of cases of sexual violence against boys reported in Porto Alegre. Paidéia, 24(58), 187-195.

Hohendorff, J., von, Habigzang, L. F., \& Koller, S. H. (2012). Violência sexual contra meninos: dados epidemiológicos, características e consequências. Psicologia USP, 23(2), 395-415.

Leal, M. L. P. (1999). A exploração sexual comercial de meninos, meninas e adolescentes na América Latina e Caribe - Relatório final - Brasil. Brasília, DF: Centro de Referência, Estudos e Ações sobre Crianças e Adolescentes.

Libório, R. M. C. (2004). Exploração sexual comercial infantojuvenil: categorias explicativas e políticas de enfrentamento. In R. M. C. Libório \& S. M. G. Souza (Orgs.), A exploração sexual de crianças e adolescentes no Brasil: reflexões teóricas, relatos de pesquisa e intervenções psicossociais (pp. 19-50). Goiânia: Casa do Psicólogo, Editora da UCG.

Libório, R. M. C. (2005). Adolescentes em situação de prostituição: uma análise sobre a exploração sexual comercial na sociedade contemporânea. Psicologia: Reflexão e Crítica, 18(3), 413-420.

Lowenkron, L. (2015). Consentimento e vulnerabilidade: alguns cruzamentos entre o abuso sexual infantil e o tráfico de pessoas para fim de exploração sexual. Cadernos Pagu, 45, 225-258.

Ministério da Saúde (2002). Notificação de maus-tratos contra crianças e adolescentes pelos profissionais de saúde. Brasília: Secretaria de Assistência à Saúde. Recuperado em 12 outubro, 2018, de http://bvsms.saude.gov.br/

Morais, N. A., Neiva-Silva, L., \& Koller, S. H. (2010). Crianças e adolescentes em situação de rua: história, caracterização e modo de vida. In N. A. Morais, L. Neiva-Silva, \& S. H. Koller (Eds.), Endereço desconhecido: crianças e adolescentes em situação de rua (pp. 35-61). São Paulo: Casa do Psicólogo.

Organização Internacional do Trabalho. (1999). Convenção n. 182, de 17 de junho de 1999. Relativa à interdição das piores formas de trabalho das crianças e à acção imediata com vista à sua eliminação. Recuperado em 4 setembro, 2018, de http:// www.oitbrasil.org.br 
Pedersen, J. R. (2009). Vitimação e vitimização de crianças e adolescentes: expressões da questão social e objeto de trabalho do Serviço Social. Revista Textos \& Contextos, 8(1), 104-122.

Vega, L. B. da S., \& Paludo, S. dos S. (2015). Exploração sexual e rede de proteção na perspectiva da vítima. Arquivos Brasileiros de Psicologia, 67(2), 47-60.

Xavier Filha, C. (2008). "O despertar de um homem" e as "marcas do silêncio" na violência contra crianças e adolescentes: gênero e relações de poder. In P. V. B. da Silva, J. E, Lopes, \& A. Carvalho (Eds.), Por uma escola que protege: a educação e o enfrentamento à violência contra crianças e adolescentes (pp. 125-160). Ponta Grossa: UEPG.

Yin, R. K. (2010). Estudo de caso: planejamento e métodos (4a ed.). Porto Alegre: Bookman.

Nota das autoras:

As autoras agradecem à Fundação Cearense de Apoio ao Desenvolvimento Científico e Tecnológico (Funcap) as bolsas de mestrado e doutorado concedidas à primeira e à segunda autora, bem como ao Conselho Nacional de Desenvolvimento Científico e Tecnológico (CNPq) a Bolsa de Produtividade (PQ 2) concedida à terceira autora e o financiamento da pesquisa (Edital Universal).

Submissão: 5.6.2016

Aceite: 27.7 .2018 